2 Sánchez-Núñez MT, Fernández-Berrocal P, Montañés J, Latorre JM. Does emotional intelligence depend on gender? The socialization of emotional competencies in men and women and its implications. Electr J Res Educ Psychol 2008; 15: 455-74 (http://www.investigacionpsicopedagogica.org/revista/new/english/ContadorArticulo.php?253).

3 Mission: Possible. Emotional Intelligence - Tactical Tips (http:// www.missionpossibleinc.com/emotional_intelligence.htm)

Mohinder Kapoor Specialty Registrar (ST5) in Old Age Psychiatry, South West Yorkshire Foundation Trust, Beckside Court, 286 Bradford Road, Batley WF17 5PW, email: moe.kapoor@nhs.net

doi: $10.1192 / \mathrm{pb} .35 .7 .276 \mathrm{~b}$

\section{Quixotic jousting over mental states}

Neither Thomas Szasz ${ }^{1}$ nor Edward Shorter ${ }^{2}$ grasps the nettle of mental pain, which is at the heart of the psychiatric experience. As in any institution, consensus in medicine is a political process; Shorter represents the one we have now, which is that doctors treat lesions. (The neurologist Henry Miller declared over 40 years ago that 'psychiatry is neurology without physical signs'. ${ }^{3}$ ) Szasz's charge is that this stance deprives patients of a responsibility to make use of the help they seek. When asked to 'to raze out the written troubles of [Lady Macbeth's] brain', Macbeth's physician is right to imply that there is more to this than cerebral pathology. Many people suffer terribly; some - like Lady Macbeth - through their own deeds, others through events or diseases beyond their control. But what is Szasz's 'active patient' to do with a doctor who only wants to look at his or her brain? Psychiatry is diminished to the extent that it cannot face the experience of patients and their desire to be understood, as well as treated.

1 Szasz T. The myth of mental illness: 50 years later. Psychiatrist 2011; 35 179-82.

2 Shorter E. Still tilting at windmills. Commentary on ... The myth of mental illness. Psychiatrist 2011; 35: 183-4.

3 Miller H. Psychiatry: medicine or magic? Br J Hosp Med 1970; 3: 122-6.

Sebastian Kraemer is a consultant child and adolescent psychiatrist, Whittington Hospital, London N19 5NF, UK, email: kraemer@doctors.org.uk

doi: 10.1192/pb.35.7.277

\section{Proportional or balanced decisions?}

I was interested to read Curtis et al's analysis of the proportionality principle and what it means in practice. ${ }^{1}$ I was intrigued as to the authors' views on the role of balancing (in the legal sense) in reaching decisions day to day in relation to patient healthcare and the competing interests related to the use of the Mental Health Act. Certainly, proportionality has been described by some as the dominant underlying theme of the European Convention on Human Rights, but others argue that the principle of balancing has had at least as prominent a role to play in UK courts. For example, there is significant variation across different jurisdictions in terms of the consistency with which the proportionality principle has been applied by the courts. Goold et al ${ }^{2}$ report that in comparison with other countries, the UK has been more likely to adopt a balancing approach - described as 'a broad brush, and sometimes opaque analysis aimed at resolution of the interests and rights involved'. This is in contrast to the multistage analysis that occurs when the proportionality principle is applied. Goold et al comment that in terms of the right of liberty, Germany is the jurisdiction which applies a strict necessity test against any deprivation of liberty, whereas UK courts have been inclined to balance rights and interests against each other. The authors liken the balancing principle to a utilitarian analysis of the rights and public interest goals in question.

Curtis et al quite rightly point out that multidisciplinary team decision-making often involves an analysis of the rights and interests of the patient and the public, and liken this to the legal principle of proportionality. I suspect in practice the decisions multidisciplinary teams make daily are more in keeping with the legal concept of balancing, and perhaps the authors refer here to proportionality in the common rather than legal sense of the word. My point here is that given the propensity of UK courts to opt for a balancing approach, it is perhaps a one-dimensional view to refer only to the principle of proportionality in relation to the Convention. Additionally, I am not convinced that there will be many clinicians who opt to make use of the four-pronged Huang test as opposed to a broad-sweep analysis when it comes to decisions in daily practice. This, of course, does not take away from the usefulness of highlighting the need for clinical decisions to be mindful of human rights, but I am not convinced that readers should feel obliged to use a multistage analysis test for clinical decisions for fear of contravening human rights legislation - as this would not appear to reflect the legal situation as it stands today.

1 Curtice M, Bashir F, Khurmi S, Crocombe J, Hawkins T, Exworthy T. The proportionality principle and what it means in practice. Psychiatrist 2011; 35: 111-6.

2 Goold B, Lazarus L, Swiney G. Public Protection, Proportionality and the Search for Balance. Ministry of Justice Research Series 10/07 (September 2007).

Rachel S. Brown is ST6 in general adult psychiatry, North Intensive Home Treatment Team, Allander House, 141 Leith Walk, Edinburgh EH6 8NP, UK, email: rachelbrown@doctors.org.uk

doi: 10.1192/pb.35.7.277a 